\author{
В.Б. Дудикевич, Г.В. Микитин, М.О. Галунець
}

Національний університет “Львівська політехніка”, Львів

\title{
СИСТЕМНА МОДЕЛЬ ІНФОРМАЦІЙНОЇ БЕЗПЕКИ “РОЗУМНОГО МІСТА”
}

У контексті розгортання Концепиії 4.0 в Україні запропоновано системну модель інформаційної безпеки “розумного міста" на рівні: його сегментів; складових - “розумних об'єктів" та багаторівневих кіберфізичних систем (КФС) “фізичний простір (ФП) - комунікачійне середовище (КС) - кібернетичний простір (КП)”; загроз рівням КФС, компонентам рівня та процесам, щзо відповідають рівню: відбиранню інформаиії, передаванню/прийманню, обробленню, управлінню; технологій забезпечення безпеки структури та функиіоналу сегменту “розумного міста" за профілями - конфідениійність, иілісність, доступність. Модель розгорнута для сегментів: “розумна енергетика”, “розумне довкілля”, “розумна медицина”, “розумна інфраструктура" і побудована за принципами системного аналізу - иілісності, ієрархічності, багатоаспектності. Системна модель на основі КФС дозволяє створювати комплексні системи безпеки (КСБ) “розумних об'єктів” відповідно до: конщепиії “об’єкт-загроза - захист”, універсальної платформи “загрози профілі безпеки - інструментарій”, методологічних підходів до багаторівневого захисту інформації, функиіональних процесів захищеного обміну. Така системна структура може бути використана також для забезпечення гарантоздатності системи “розумний об'єкт - кіберфізична технологія” у просторі функиіональної та інформаційної безпеки. Проаналізовано безпеку MEMS-давачів як компоненти інтернету речей у ФП кіберфізичних систем: загрози - лінійні навантаження, власні иуми елементів схеми, температурні залежності, зношуваність; технології захисту - лінійні стабілізатори, термотривкі елементи, охолодження, покращання технології виготовлення, методи отримання нових матеріалів та покращання властивостей. На протидію перехопленню інформації в безпровідних каналах зв'язку, характерної розумним об'єктам, розглянуто алгоритм блокового шифрування даних AES в сенсорних мережах з програмною реалізацією мовою програмування С\#. Проаналізовано безпеку хмарних технологій як компоненти КС кіберфізичних систем на апаратно-програмному рівні та наведено особливості криптографічних систем шифрування даних в хмарних технологіях відповідно до нормативного забезпечення.

Ключові слова: “розумне місто”, інформаџійна безпека, системна модель, кіберфізична система, інтернет речей, хмарні технології, иифрування даних, криптографічні системи.

\section{Вступ}

Постановка проблеми. Українська стратегія Індустрії 4.0 та проект Концепції інформаційної безпеки (ІБ) України розгортають процеси проектування безпечних об'єктів інтелектуалізації промисловості, енергетики, інфраструктури [1-2]. Парк засобів безпечного функціонування "розумних міст" охоплює багаторівневі кіберфізичні системи (КФС) і технології їх безпеки, як інструментарій забезпечення ІБ процесів: відбирання - передавання/приймання оброблення - управління за відповідними профілями [3-4]. Безпека інфраструктури "розумного міста" обумовлюється роботоздатністю об'єктів та гарантоздатністю - інформаційних систем - їх функціональною та інформаційною безпекою (СОУ-Н НКАУ 0060:2010). Актуальним є розвиток підходів до забезпечення ІБ “розумних об’єктів” на основі КФС.

Аналіз останніх досягнень і публікацій. У просторі Концепції “Індустрія 4.0” в Україні розгортаються рішення щодо проектування “розумних міст” та можливостей їх реалізації на базі структури “сенсорна мережа - центральна платформа даних - мобільні додатки" [5]. Актуальні стандарти BSI (Британський Інститут стандартів) щодо концепції і моделей створення “розумних міст” та впровадження технологій безпеки, зокрема за стандартом PAS 185: 2017 [6]. В працях [7-8] розгорнуто концепцію безпечного “розумного міста", аспекти моделювання як складову управління безпечним містом; проаналізовано атаки на IT-структуру міста, запропоновано комплекс заходів щодо покращення його безпеки. Безпечне функціонування інтернету речей в концепції "розумного міста" обумовлюється безпекою давачів і сенсорних мереж. В роботі [9] авторами: запропоновано архітектуру концепції інтернету речей, розглянуто розподіл DoS-атак в безпровідній сенсорній мережі за рівнями моделі OSI та механізми протидії. В праці [10] розвинуто інформаційну безпеку сенсорних мереж Zigbee, Wi-Fi та Bluetooth у просторі “рівень OSI - функції - протоколи” на основі концепції “об'єкт - загроза - захист” та нормативного забезпечення. Засадами забезпечення ІБ хмарних обчислень є міжнародні стандарти, нормативні та керівні документи, які розроблені Cloud Security Alliance (CSA), Свропейським агентством 
мережної та інформаційної безпеки (ENISA) і Національним інститутом стандартів і технологій (NIST), що регламентують правові, організаційні і технічні складові ІБ хмарних обчислень [11]. В праці [12] розглянуто загрози і заходи забезпечення безпеки користувачів і провайдерів послуги $\mathrm{PaaS}$ (“платформа як сервіс"). Актуальним є запит на системну модель інформаційної безпеки "розумного міста" на основі КФС, що є розвитком підходів до створення ефективних КСБ на всіх етапах життєвого циклу інформації.

Мета статті. Метою роботи є створення системної моделі безпечного "розумного міста" на основі КФС згідно концепції “об’єкт - загроза захист”, яка $\epsilon$ підгрунтям для побудови КСБ “розумних об’єктів” на базі платформи “загрози - профілі інструментарій” для забезпечення конфіденційності, цілісності, доступності.

\section{Виклад основного матеріалу}

Системна модель безпеки "розумного міста" (РМ) створена на основі концепції “об' єкт - загроза - захист” і є багаторівневою (рис. 1). Перший рівень - функціональний, що забезпечує роботоздатність системи “складові "розумного міста" - технології функціонування/ “розумні об’єкти” $\left(\mathrm{O}_{1-\mathrm{N}(\mathrm{R}, \mathrm{S}, \mathrm{T})}\right)$ - кіберфізичні системи (КФС 1 -N(R,S,T) $)$ " відповідно до сегментів - розумна енергетика (РЕ), розумне довкілля (РД), розумна медицина (РМ), розумна інфраструктура (PI). Другий рівень - інтеграції рівнів КФС “фізичний простір $\left(Ф \Pi_{1-\mathrm{N}(\mathrm{R}, \mathrm{S}, \mathrm{T})}\right)$ - комунікаційне середовище $\left(\mathrm{KC}_{1-\mathrm{N}(\mathrm{R}, \mathrm{S}, \mathrm{T})}\right)$ - кібернетичний простір $\left(\mathrm{K}_{1-\mathrm{N}(\mathrm{R}, \mathrm{S}, \mathrm{T})}\right)$ ” та інтеграції компонент одного рівня. Третій рівень - процеси “відбирання інформації ( $\mathrm{B}_{1-}$ $\mathrm{N}(\mathrm{R}, \mathrm{S}, \mathrm{T})$ )/ контролю - передавання/приймання (ПРД $\mathrm{N}(\mathrm{R}, \mathrm{S}, \mathrm{T}) /$ ПPM $\left._{1-\mathrm{N}(\mathrm{R}, \mathrm{S}, \mathrm{T})}\right) \quad$ - оброблення інформації $\left(\mathrm{O}_{1-}\right.$ $\mathrm{N}(\mathrm{R}, \mathrm{S}, \mathrm{T})$ / управління $\left(\mathrm{Y}_{1-\mathrm{N}(\mathrm{R}, \mathrm{S}, \mathrm{T})}\right)$ ”. Четвертий рівень загрози ІБ на структурно-функціональному рівні КФС $\left(\mathrm{a}_{1-\mathrm{N}}-\mathrm{b}_{1-\mathrm{N}}-\mathrm{c}_{1-\mathrm{N}}(\mathrm{PE}) ; \mathrm{d}_{1-\mathrm{R}}-\mathrm{e}_{1-\mathrm{R}}-\mathrm{f}_{1-\mathrm{R}}(\mathrm{PД}) ; \mathrm{g}_{1-\mathrm{S}}-\right.$ $\left.\mathrm{h}_{1-\mathrm{S}}-\mathrm{i}_{1-\mathrm{S}}(\mathrm{PM}) ; \mathrm{k}_{1-\mathrm{T}}-\mathrm{l}_{1-\mathrm{T}}-\mathrm{m}_{1-\mathrm{T}}(\mathrm{PI})\right)$. П'ятий рівень апаратно-програмні технології безпеки за профілями “конфіденційність - цілісність - доступність” ( $\mathrm{A}_{1-\mathrm{N}}-$ $\mathrm{B}_{1-\mathrm{N}}-\mathrm{C}_{1-\mathrm{N}}(\mathrm{PE}) ; \mathrm{D}_{1-\mathrm{R}}-\mathrm{E}_{1-\mathrm{R}}-\mathrm{F}_{1-\mathrm{R}}(\mathrm{P} Д) ; \mathrm{G}_{1-\mathrm{S}}-\mathrm{H}_{1-\mathrm{S}}-\mathrm{I}_{1-\mathrm{S}}$ (PM); $\mathrm{K}_{1-\mathrm{T}}-\mathrm{L}_{1-\mathrm{T}}-\mathrm{M}_{1-\mathrm{T}}(\mathrm{PI})$ ).

Безпечне відбирання даних від давачів “розумних об'єктів" та обмін інформації в “розумному місті” відповідно здійснюють інтернет речей (ФП) і хмарні технології (КС). Кібернетичний простір, як платформа даних, забезпечує зберігання, аналіз, оброблення даних, візуалізацію, прогнозування i, на цій основі, управління ситуаціями в режимі реального часу.

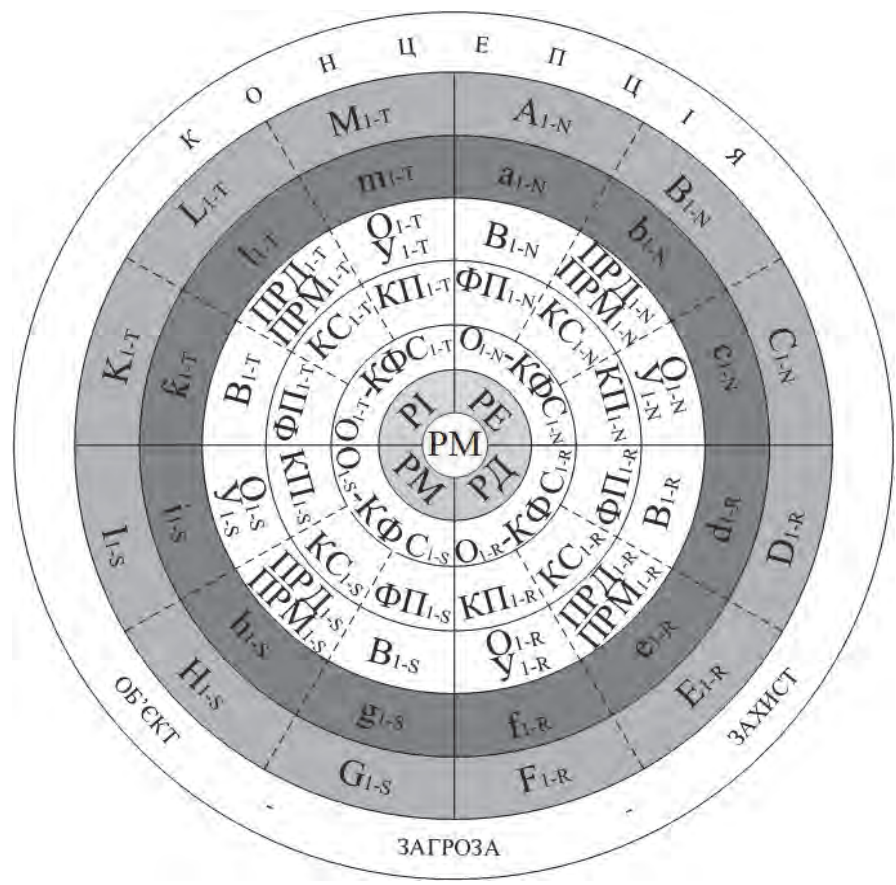

Рис. 1. Структура моделі безпеки “розумного міста” на основі концепції “об’єкт - загроза - захист”

Інтернет речей: безпека МЕМС-давачів, шифрування даних в сенсорних мережах. Фізичний простір КФС пов'язаний з інтернет речей, як мережею давачів (спеціалізованих, MEMS), які реєструють інформацію 3 досліджуваних фізичних об’єктів відповідного сегменту, передають іiї сенсо- рними мережами, зокрема такими як ZigBee, Wi-Fi, Bluetooth у кібернетичний простір, наприклад у вбудований комп'ютер для оброблення даних та ідентифікації стану об'єкта i, на цій основі, прийняття рішення на управління станом об’єкта. 
MEMS-давачі - це технології і пристрої, що поєднують в собі мікроелектронні і мікромеханічні компоненти, які поділяються на два типи: давачі /сенсори - вимірювальні пристрої, які перетворюють вхідний фізичний вплив в електричний сигнал; виконавчі пристрої - системи, які здійснюють перетворення вхідного сигналу у вихідну дію. MEMSдавачі забезпечують функціональну взаємодію фізичного та кібернетичного просторів КФС на рівні процесів “відбирання - передавання/приймання оброблення - управління” і характеризуються високою точністю, відмовостійкістю та мініатюрними розмірами. Безпека MEMS-давачів обумовлює безпечне функціонування КФС у контексті забезпечення конфіденційності, цілісності, доступності інформації у сегментах “розумного міста”. Для MEMSдавачів характерні такі загрози: лінійні навантаження, власні шуми елементів схеми, температурні залежності, зношуваність. 3 метою попередження загроз на практиці використовуються такі елементи захисту MEMS-давачів: лінійні стабілізатори, термотривкі елементи, охолодження, покращання технології виготовлення, методи отримання нових матеріалів та покращання властивостей.

Однією із загроз, що зустрічається в усіх сегментах розумного міста, $є$ перехоплення інформації в безпровідних каналах зв'язку. Серед технологій безпеки застосовують обмеження доступу до каналів зв'язку та шифрування даних. Криптографічний захист інформації в сенсорних мережах реалізовано на основі алгоритму блокового шифрування даних (AES) (рис. 2).

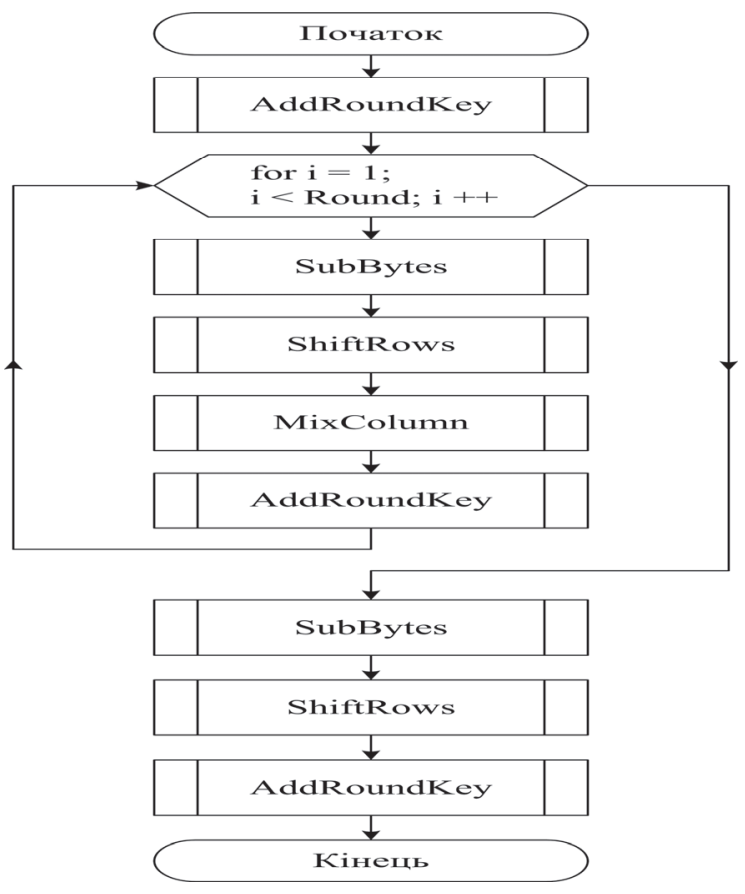

Рис. 2. Алгоритм шифрування даних AES
На рис. 3 наведено скріншот програмної реалізації блокового шифрування даних мовою програмування С\#.

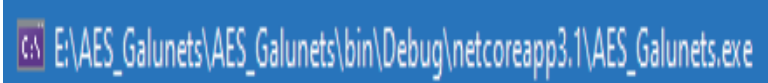 \\ Enter text that will be encrypted: \\ Hello world! Some test text.

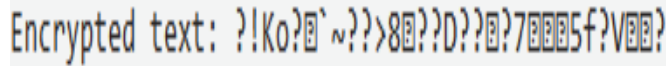 \\ Encryption completed.}

Рис. 3. Скріншот програми шифрування даних

Безпека хмарних технологій. Для багаторівневої структури КФС актуальною є схема передавання/приймання даних засобами КС із застосуванням технологій закриття інформації.

3 позиції забезпечення ІБ хмарних технологій характерні такі апаратні загрози: несанкціонований фізичний доступ до обладнання та серверів хмари; відмови, збої, аварії обладнання; помилки при конфігуруванні. Прикладом програмних загроз є: несанкціонований віддалений доступ до ресурсів хмари; шкідливе програмне забезпечення; експлойти.

Апаратний захист хмарних технологій передбачає: обмеження доступу до обладнання та серверів; використання сертифікованого обладнання; ведення журналу дій користувачів.

На програмному рівні захисту застосовуються: ідентифікація, аутентифікація користувачів хмарних ресурсів; шифрування даних; своєчасне оновлення програмного та антивірусного забезпечення. Для шифрування даних в хмарних технологіях використовуються спеціалізовані криптографічні системи, деякі з яких наведено в табл. 1.

\section{Висновки}

Системна модель безпечного "розумного міста" є універсальною в контексті застосування КФС як технологій підтримки сегментів - РЕ. РД, РМ, РІ т.ін. Вона передбачає побудову комплексних систем безпеки КФС на основі: концепції “об’єкт - загроза - захист”; платформи “загрози - профілі безпеки інструментарій”; підходів для кожного сегментного рівня КФС; функціональних процесів відповідно до задач безпеки (ДСТУ ISO/ IEC 15408). 
Таблиця 1

Характеристика криптографічних систем для шифрування даних в хмарних технологіях

\begin{tabular}{|c|c|c|c|}
\hline $\begin{array}{c}\text { Назва } \\
\text { системи }\end{array}$ & Алгоритм роботи & Особливості & $\begin{array}{c}\text { Нормативне } \\
\text { забезпечення }\end{array}$ \\
\hline 1 & 2 & 3 & 4 \\
\hline Гряда-61 & $\begin{array}{l}\text { AES-128, AES-192, } \\
\text { AES-256, SHA-256; }\end{array}$ & $\begin{array}{l}\text { - Криптомодуль виконаний у вигляді малогабаритного USB- } \\
\text { пристрою, ше під'єднується до ЕОМ за допомогою незнім- } \\
\text { ного кабелю; } \\
\text { - Швидкість формування ЕЦП за } 257 \text { - } 100 \text { мс.; } \\
\text { - Швидкість формування спільного секрету Діффі-Гелмана } \\
\text { в групі точок еліптичної кривої, поле } 571 \text { - } 800 \text { мс.; } \\
\text { - Зберігання особистих ключів та інших ключових даних } \\
\text { здійснюється у внутрішньому постійному за- } \\
\text { пам'ятовуючому пристрої криптомодуля; }\end{array}$ & $\begin{array}{l}- \text { ДСТУ 28147: } \\
\text { 2009; } \\
\text { - ДСТУ 4145: } \\
\text { 2002; } \\
\text { - ДСТУ 7564: } \\
\text { 2014; } \\
\text { - FIPS 140-2; }\end{array}$ \\
\hline Бар'єр-301 & $\begin{array}{l}\text { AES-128, AES-192, } \\
\text { AES-256, SHA-256; }\end{array}$ & $\begin{array}{l}\text { - Автентифікація клієнтів захисту при підключенні до } \\
\text { сервера; } \\
\text { - Прийом та дешифрування /шифрування даних ТСР- } \\
\text { з'єднання від клієнта/сервера та передачі їх на сер- } \\
\text { вер/клієнт; } \\
\text { - Кількість автентифікачій клієнтів- } 100 / \text { с.; } \\
\text { - Швидкість шифрування - } 250 \text { Мбіт/с.; }\end{array}$ & $\begin{array}{l}\text { - ДСТУ } 7564 \text { : } \\
2014 ; \\
\text { - FIPS 140-2; } \\
\text { - FIPS 180-3; } \\
\text { - RFC 4634; }\end{array}$ \\
\hline SSL & $\begin{array}{l}\text { RSA, Diffie- } \\
\text { Hellman, ECDH, } \\
\text { SRP, PSK, RC2, } \\
\text { RC4, IDEA, DES, } \\
\text { Triple DES, AES, } \\
\text { Camellia; }\end{array}$ & $\begin{array}{l}\text { - Для шифрування використовується асиметричний алго- } \\
\text { ритм з відкритим ключем; } \\
\text { - При шифруванні з відкритим ключем використовується } \\
\text { два ключі; } \\
\text { - Для шифрування може використовуватись будь-який } 3 \\
\text { двох ключів; }\end{array}$ & $\begin{array}{l}-R F C \quad 2401- \\
2412 ;\end{array}$ \\
\hline Luna SP & $\begin{array}{l}\text { 3DES, AES, RC2, } \\
\text { RC4, RC5, CAST- } \\
\text { 128, } \\
\text { Hellman, Diffie- } \\
\text { DSA, HMAC-MD5, } \\
\text { HMACSHA-1, } \\
\text { SSL3-MD5-MAC, } \\
\text { SSL3-SHA-1-MAC, } \\
\text { SHA-1, SHA-2 } \\
\text { SHA-224, SHA-256, } \\
\text { SHA-384, SHA-512, } \\
\text { MD-5 }\end{array}$ & $\begin{array}{l}\text { - Двофакторна аутентифікаиія і багаторівневий контроль } \\
\text { доступу; } \\
\text { - Автоматичний перезапуск додатків; } \\
\text { - Стандартне середовище розробки; } \\
\text { - Продуктивність до } 7000 \text { перетворень за } 1 \text { с.; } \\
\text { - SafeNet Luпа SP об'єднує в собі функиіонал сервера додат- } \\
\text { ків Јаvа і захищеність апаратного модуля безпеки. }\end{array}$ & $\begin{array}{l}- \text { PKCS } \\
\text { v1.5; } \\
\text { - OAEP PKCS } \\
\text { \#1 v2.0; } \\
\text { - FIPS } 140-2 \text {. }\end{array}$ \\
\hline $\begin{array}{l}\text { CryptoLine } \\
358\end{array}$ & $\begin{array}{l}\text { AES-128, AES-192, } \\
\text { AES-256, SHA-256, } \\
\text { DES, 3-DES, RSA }\end{array}$ & $\begin{array}{l}\text { - Ініціалізація і персоналізація ключових елементів систем; } \\
\text { - Генерація і зберігання ключової інформацї̈; } \\
\text { - Шифрування / дешифрування електронних документів зі } \\
\text { швидкістю більш } 20 \text { Мбіт / с.; } \\
\text { - Інтерфейс - USB 2.0. }\end{array}$ & $\begin{array}{l}\text { - ДСТУ 4145: } \\
2002 ; \\
\text { - ДСТУ 7564: } \\
2014 ; \\
\text { - ДСТУ } \\
\text { ISO/IEC 9798- } \\
\text { 3: 2002; } \\
\text { - FIPS 140-2; } \\
\text { - FIPS 180-3; } \\
\text { - RFC 4634; } \\
\text { - FIPS 46-3. }\end{array}$ \\
\hline Thales & $\begin{array}{l}\text { AES (256-bit key), } \\
\text { Blowfish (448-bit } \\
\text { key), CAST5 (128- } \\
\text { bit key), Serpent } \\
\text { (256-bit key), Triple } \\
\text { DES, Twofish (256- } \\
\text { bit key) }\end{array}$ & $\begin{array}{l}\text { - Шифрування баз даних за допомогою криптографічних } \\
\text { ключів; } \\
\text { - Підтримка функиії збереження даних та їх аварійного } \\
\text { відновлення. }\end{array}$ & $\begin{array}{l}\text { - ДСТУ } \\
\text { 28147:2009; } \\
\text { - FIPS 140-2; } \\
\text { - FIPS 180-3; } \\
\text { - RFC 4634; } \\
\text { - FIPS 46-3; } \\
\text { - RFC } 2144\end{array}$ \\
\hline S/MIME & $\begin{array}{l}\text { RSA, Diffie- } \\
\text { Hellman, DSA, } \\
\text { ECDSA, RC4, } \\
\text { IDEA, Triple } \\
\text { DES, } \\
\text { AES, MD5, SHA, } \\
\text { SHA-256/384. }\end{array}$ & $\begin{array}{l}\text { - Забезпечення криптографічної безпеки електронної по- } \\
\text { шти; } \\
\text { - Аутентифікація, иілісність повідомлення, гарантія збе- } \\
\text { реження авторства і безпека даних (у частині шифруван- } \\
\text { ня); } \\
\text { - Підтримка S/МІМЕ великою частиною сучасних пошто- } \\
\text { вих програм. }\end{array}$ & • PKCS \# 7. \\
\hline
\end{tabular}




\section{Список літератури}

1. Юрчак Олександр. Українська стратегія Індустрії 4.0 - 7 напрямів розвитку [Електронний ресурс]. - Режим доступу: https://industry4-0-ukraine.com.ua/2019/01/02/ukrainska-strategiya-industrii-4-0-7-napriankiv-rozvutku/.

2. Проект Концепції інформаційної безпеки України [Електронний ресурс]. - Режим доступу: http://mip.gov.ua/done_img/d/30-project_08_06_15.pdf.

3. Мельник А.О. Наукові напрями створення багаторівневої платформи кіберфізичних систем / А.О. Мельник // Кіберфізичні системи досягнення та виклики: матеріали третього наукового семінару, 13-14 червня, 2017 р., Львів. - 2017. - C. 4-9.

4. Дудикевич В.Б. Квінтесенція безпеки кіберфізичних систем / В.Б. Дудикевич, Г.В. Микитин, А.І. Ребець // Інформаційні системи і мережі. - 2018. - № 887. - С. 58-69.

5. Імас О.Теорія рішень "розумного" міста та можливості іiі реалізації на базі єдиної муніципальної платформи [Електронний ресурс] / О. Імас, А. Бугар. - Режим доступу: https://hub.kyivstar.ua/news/teoriya-reshenij-umnogo-goroda-ivozmozhnosti-ee-realizaczii-na-baze-edinoj-municzipalnoj-platformy/.

6. PAS 185:2017. Smart Cities. Specification for establishing and implementing a security-minded approach. BSI 2017.

7. Lacinák Maroš. Smart City, Safety and Security / Maroš Lacinák, Jozef Ristvej // Procedia Engineering, 2017, TRANSCOM 2017: International scientific conference on sustainable, modern and safe transport.- 2017. - Vol. 192. P. 522-527. http://dx.doi.org/10.1016/j.proeng.2017.06.090.

8. Popescul Daniela. Data Security in Smart Cities: Challenges and Solutions / Daniela Popescul, Laura Diana Radu // Informatica Economică. - No. 1/2016. - Vol. 20. - P. 29-38. https://doi.org/10.12948/issn14531305/20.1.2016.03.

9. Дослідження вразливостей сенсорних підмереж архітектури Інтернету речей до різних типів атак / М. Алєксандер, О. Корченко, М. Карпінський, Р. Одарченко // Безпека інформації. - 2016. - Т. 22, № 1. - С. 12-19.

10. Безпровідні сенсорні мережі Zigbee, Wi-Fi та Bluetooth в кіберфізичних системах: концепція “об' єкт - загроза захист” на основі моделі OSI / В.Б. Дудикевич, Г.В. Микитин, А.І. Ребець, М.В. Мельник // Системи обробки інформації. - 2019. - № 2(157). - C. 114-120. https://doi.org/10.30748/soi.2019.157.16.

11. Аулов І.Ф. Хмарні обчислення та аналіз питань інформаційної безпеки в хмарі / І.Ф. Аулов, І.Д. Горбенко // Прикладная радиоэлектроника: науч.-техн. журнал. - 2013. - Том 12. - № 2. - С. 194-201.

12. Поночовний Ю.Л. Аналіз загроз і заходів із забезпечення безпеки в системах хмарних обчислень 3 послугою PaaS / Ю.Л. Поночовний, I.O. Черницька, I.В. Замковець // Збірник наукових праць Харківського університету Повітряних Сил. - 2016. - Вип. 3(48). - С. 104-107.

\section{References}

1. Yurchak, Oleksandr (2019), "Ukrainska stratehiia Industrii 4.0 - 7 napriamiv rozvytku” [Ukrainian Industry Strategy 4.0 - 7 trends]", available at: https://industry4-0-ukraine.com.ua/2019/01/02/ukrainska-strategiya-industrii-4-0-7-napriankivrozvutku/.

2. "Proekt Kontseptsii informatsiinoi bezpeky Ukrainy" [Draft Concept of Information Security of Ukraine], available at: www.mip.gov.ua/done_img/d/30-project_08_06_15.pdf.

3. Melnyk, A.O. (2017), "Naukovi napriamy stvorennia bahatorivnevoi platformy kiberfizychnykh system" [Scientific directions of creation of a multilevel platform of cyber physical systems], Kiberfizychni systemy dosiahnennia ta vyklyky: materialy tretoho naukovoho seminaru, 13-14 chervnia, Lviv, pp. 4-9.

4. Dudykevych, V.B., Mykytyn, H.V. and Rebets, A.I. (2018), "Kvintesentsiia bezpeky kiberfizychnykh system" [Security quintessence of cyber-physical systems], Informatsiini systemy i merezhi, No. 887, pp. 58-69.

5. Imas, O. and Bughar, A. (2019), "Teoriia rishen "rozumnoho" mista ta mozhlyvosti yii realizatsii na bazi yedynoi munitsypalnoi platform" [The theory of "smart" city solutions and the possibility of its implementation on the basis of a single municipal platform], available at: https://hub.kyivstar.ua/news/teoriya-reshenij-umnogo-goroda-i-vozmozhnosti-ee-realizaczii-na-bazeedinoj-municzipalnoj-platformy/.

6. British Standards Institution (2017), PAS 185:2017. Smart Cities. Specification for establishing and implementing a security-minded approach.

7. Lacinák, Maroš and Ristvej, Jozef (2017), Smart City, Safety and Security, Procedia Engineering, Vol. 192, pp. 522-527. http://dx.doi.org/10.1016/j.proeng.2017.06.090.

8. Popescul, Daniela and Radu, Laura Diana (2016), Data Security in Smart Cities: Challenges and Solutions, Informatica Economică, No. 1/2016, Vol. 20, pp. 29-38. https://doi.org/10.12948/issn14531305/20.1.2016.03.

9. Alieksander, M., Korchenko, O., Karpinskyi, M. and Odarchenko, R. (2016), "Doslidzhennia vrazlyvostei sensornykh pidmerezh arkhitektury Internetu rechei do riznykh typiv atak" [Investigation of Sensitive Subnetwork Vulnerabilities of the Internet of Things Architecture to Different Types of Attacks], Bezpeka informatsii, Vol. 22, No. 1, pp. 12-19.

10. Dudykevych, V.B., Mykytyn, H.V., Rebets, A.I. and Melnyk, M.V. (2019), "Bezprovidni sensorni merezhi Zigbee, WiFi ta Bluetooth v kiberfizychnykh systemakh: kontseptsiia "obiekt - zahroza - zakhyst" na osnovi modeli OSI" [Zigbee, Wi-Fi and Bluetooth Wireless Sensor Networks in Cyber-Physical Systems: OSI Modeled Object-Threat-Protection Concept], Information Processing Systems, No. 2(157), pp. 114-120. https://doi.org/10.30748/soi.2019.157.16.

11. Aulov, Y.F. and Gorbenko, Y.D. (2013), "Khmarni obchyslennja ta analiz pytanj informacijnoji bezpeky v khmari" [Cloud computing and information security analysis in the cloud], Applied Electronics, Vol. 12, No. 2, pp. 194-201.

12. Ponochovnyi, Yu.L., Chernytska, I.O. and Zamkovets, I.V. (2016), "Analiz zahroz i zakhodiv iz zabezpechennia bezpeky v systemakh khmarnykh obchyslen z posluhoiu PaaS" [Analysis of threat and entry and security of bezpekah in the systems of the most depreciated servants PaaS], Scientific Works of Kharkiv National Air Force University, No. 3(48), pp. 104-107. 
Відомості про авторів:

Дудикевич Валерій Богданович

доктор технічних наук професор

завідувач кафедри

Національного університету “Львівська політехніка",

Львів, Україна

https://orcid.org/0000-0001-8827-9920

\section{Микитин Галина Василівна}

доктор технічних наук професор

професор кафедри

Національного університету “Львівська політехніка",

Львів, Україна

https://orcid.org/0000-0003-4275-8285

\section{Галунець Максим Олексійович}

студент

Національного університету "Львівська політехніка",

Львів, Україна

https://orcid.org/0000-0001-9574-3576
Information about the authors:

Valeriy Dudykevych

Doctor of Technical Sciences Professor

Head of Department

of Lviv Polytechnic National University,

Lviv, Ukraine

https://orcid.org/0000-0001-8827-9920

Galyna Mykytyn

Doctor of Technical Sciences Professor

Professor of Departmen

of Lviv Polytechnic National University,

Lviv, Ukraine

https://orcid.org/0000-0003-4275-8285

Maksym Halunets

Student

of Lviv Polytechnic National University,

Lviv, Ukraine

https://orcid.org/0000-0001-9574-3576

\title{
СИСТЕМНАЯ МОДЕЛЬ ИНФОРМАЦИОННОЙ БЕЗОПАСНОСТИ "УМНОГО ГОРОДА"
}

\author{
В.Б. Дудыкевич, Г.В. Микитин, М.А. Галунец
}

В контексте развертывания Концепции 4.0 в Украине предложена системная модель информационной безопасности “умного города" на уровне: его сегментов; составляющих - “умных объектов” и многоуровневых киберфизических систем физическое пространство - коммуникачионная среда - кибернетическое пространство”; угроз уровням киберфизической системь, компонентам уровня и прочессам, отвечающим уровню: отбора информации, передачи/приема, обработки, управления; технологий обеспечения безопасности структуры и функиионала сегмента "умного города" по профилям - конфиденциальность, иелостность, доступность. Модель развернута для сегментов: “умная энергетика”, “умная окружающая среда", “умная медичина", “умная инфраструктура" и построена по принципам системного анализа - целостности, иерархичности, многоаспектности. Системная модель на базе киберфизических систем позволяет создавать комплексные системы безопасности “умных объектов" в соответствии с: концепиией “объект угроза - зашита”, универсальной платформой “угрозы - профили безопасности - инструментарий”, методологическими подходами к многоуровневой защите информации, функциональными процессами защищенного обмена. Такая системная структура может быть использована для обеспечения гарантоспособности системы "умный объект киберфизическая технология” в пространстве функичиональной и информационной безопасности. Проанализирована безпасность MEMS-датчиков в качестве компоненты интернета вещей в физическом пространстве киберфизических систем: угрозы - температурные зависимости, линейные нагрузки, собственные иумы элементов схемы, изнашиваемость; технологии защиты - линейные стабилизаторы, жаропрочные элементы, охлаждение, улучшение технологии изготовления, методы получения новых материалов и улучшения свойств. В противодействие перехвату информации в беспроводных каналах связи рассмотрен алгоритм блокового иифрования данных AES в сенсорных сетях с программной реализачией на языке програмлирования С\#. Проанализирована безопасность облачных технологий в качестве компоненты коммуникаиионной среды киберфизических систем на аппаратно-программном уровне и приведены особенности криптографических систем шифрования данных в облачных технологиях согласно нормативному обеспечению.

Ключевые слова: “умный город”, информационная безопасность, системная модель, киберфизическая система, интернет вещей, облачные технологии, шифрование данных, криптографические системь.

\section{SYSTEMIC MODEL OF "SMART CITY" INFORMATION SECURITY}

\section{Dudykevych, G. Mykytyn, M. Halunets}

In the context of the deployment of Concept 4.0 in Ukraine, a systematic model of "smart city" information security was proposed at the level of: its segments; constituents - "smart objects" and multilevel cyber-physical systems "physical space communication environment - cybernetic space"; threats to cyber-physical systems levels, level components and processes appropriate to the level: selecting the information , transferring / receiving, processing, management; technologies for ensuring the security of the structure and functionality of the "smart city" segment by profiles - confidentiality, integrity, accessibility. The model is deployed for segments: "smart energy", "smart environment", "smart medicine", "smart infrastructure" and is built on the principles of system analysis - integrity, hierarchy, multidimensionality. The cyber-physical systems-based system model enables the creation of integrated security systems of "smart objects" in accordance with: the concept of "object - threat - protection", the universal platform "threats - security profiles - tools", methodological approaches to multilevel information protection, functional processes of secure exchange. Such a systemic structure can also be used to ensure warranty of the "smart object - cyberphysical technology" system in the functional and information security space. The safety of MEMS-sensors as components of the Internet of Things in cyber physical systems is analyzed: threats - linear loads, inherent noise of circuit elements, temperature dependencies, wear and tear; protection technologies - linear stabilizers heat-resistant elements, cooling, improvements in manufacturing technology, methods of obtaining new materials and improvement of properties. To counteract the interception of information in wireless communication channels characteristic of smart objects, the algorithm of block encryption of data AES on sensor networks with software implementation in C\# programming language is considered. The security of cloud technologies as a component of communication environment of the cyber-physical systems at hardware and software level is analyzed and features of cryptographic data encryption systems in cloud technologies are given in accordance with the normative software.

Keywords: "smart city", information security, systemic model, cyber-physical system, Internet of Things, cloud technology, data encryption, cryptographic systems. 